\title{
CONSTRUÇÃO DA IDENTIDADE DOCENTE: RELATOS DE EDUCADORES DE EDUCAÇÃO INFANTIL
}

\section{ZILMA DE MORAES RAMOS DE OLIVEIRA}

Faculdade de Educação da Universidade de São Paulo zilmaoliveira@uol.com.br

\section{ANA PAULA SOARES SILVA}

Faculdade de Filosofia Ciências e Letras da Universidade de São Paulo-Ribeirão Preto ap_soaressilva@yahoo.com.br

\section{FERNANDA MORENO CARDOSO}

Mestre em Lingüística Aplicada pela Pontifícia Universidade Católica de São Paulo fecardoso@uol.com.br

\section{SILVANA DE OLIVEIRA AUGUSTO}

Mestranda da Faculdade de Educação da Universidade de São Paulo silvana_augusto@uol.com.br

\section{RESUMO}

No intuito de colaborar para a compreensão das relações aprendizagem-identidade e teoria-prática que os professores participantes de curso de formação docente estabelecem, e de como elas são afetadas pelas experiências formativas, foram analisados textos produzidos como Trabalho de Conclusão de Curso - TCC - por alunos de um programa de formação inicial docente em serviço de nível médio, orientados pela perspectiva teórico-metodológica denominada rede de significações.

EDUCAÇÃO INFANTIL - PROFESSORES - FORMAÇÃO DE PROFESSORES IDENTIDADE

\section{ABSTRACT}

CONSTRUCTION OF THE TEACHING IDENTITY: STORIES OF EDUCATORS OF EARLY CHILDHOOD EDUCATION. This work has a double goal: a) to provide evidences that help to understand learning-identity and theory-practice relationships constructed during a teacher-education formation program; and, b) to identify if such relationships are modified by the formative experiences. At the end of the program, each participant produced a paper 
in a self-narrative form, that was analyzed through a theoretic-methodological perspective that is known as Network of Meanings.

EARLY CHILDHOOD EDUCATION - TEACHERS - TEACHEREDUCATION - IDENTITY

Existe hoje um consenso segundo o qual se afirma que o professor não deve ser visto apenas como um técnico em questões de ensino, mas como pessoa em processo de construir mudanças em sua identidade e no "sentido de si”. Todo professor tem algum tipo de discurso sobre sua prática pedagógica, elaborado pela apropriação de uma sabedoria relacionada a experiências concretas que the dão pistas orientadoras para sua ação, sendo a reflexividade uma ferramenta para a construção de conhecimento sobre qualquer atividade (Seeger, 200I). Assim, discussões sobre programas de formação docente devem investigar como a relação do professor com o seu próprio processo de aprender é neles trabalhada e de que maneira ocorre a construção de sua identidade docente (Fontana, 2000; Gatti, 2003; Maués, 2003; Oliveira, 1978; Oliveira-Formosinho, 2002; Perrenoud, 2002).

O desenvolvimento pessoal e profissional de um professor é um processo complexo e tecido conforme ele se posiciona em relação a múltiplas e, por vezes, contraditórias situações. Para tanto, contribuem também múltiplos e, por vezes, contraditórios significados, pontos de vista, valores morais, crenças expressos pelos discursos elaborados por vários interlocutores que se situam nos diferentes contextos criados nas instituições sociais, nos vários campos científicos, nas legislações, nas experiências sindicais etc.

Para conhecer mais sobre o processo de formação docente, a realidade dos profissionais da educação infantil constitui campo fértil de investigação. Há já vários anos, o trabalho em creche vive um período de transição entre uma concepção que o definia como de cunho assistencial para outra, que passou a acentuar a dimensão pedagógica de educação e cuidado de crianças bem pequenas. As novas significações em construção produzem um embate teóricoprático que acompanha a constituição de nova identidade: a de professor (Ongari, Molina, 2003).

A necessidade de atender à Lei de Diretrizes e Bases da Educação 9.394/ 1996 encarregou-se de levar essa discussão aos educadores em exercício nas creches e pré-escolas, mediante programas de formação. Para muitos desses profissionais, voltar a estudar pode significar uma transformação tanto nas suas 
condições de vida quanto em sua identidade profissional e pessoal, conforme eles são convidados a refletir sobre suas práticas - autorizadas pelos longos anos de experiência - junto às crianças e a integrar os saberes adquiridos nas atividades cotidianas com os conteúdos da formação. Tal processo implica revisar práticas, rever crenças, hábitos, ou seja, lidar com resistências a inovações (Scarpa, 1998).

No intuito de colaborar para a compreensão das relações aprendizagemidentidade e teoria-prática que os professores em formação estabelecem, e de como elas são afetadas por experiências formativas que trabalham concepções de práticas pedagógicas junto às crianças, particularmente quando mudanças significativas em paradigmas ocorrem na área, analisaremos textos produzidos como Trabalho de Conclusão de Curso - TCC - pelos alunos de um programa de formação inicial docente em serviço. O Programa ADI-Magistério desenvolveu-se sob a forma de curso normal de nível médio, tendo sido idealizado e promovido pela Secretaria Municipal de Educação de São Paulo para qualificar profissionalmente os auxiliares de educação infantil' efetivos e estáveis de suas creches diretas, denominadas Centros de Educação Infantil - CEls². Os referidos trabalhos são tratados como memoriais com características que os aproximam do formato narrativo.

A escolha de tais textos para estudo deveu-se ao fato de que a análise de narrativas, ou relatos de memórias, tem-se tornado valioso instrumento de investigação por parte de pesquisadores interessados em compreender o processo de construção da identidade e da subjetividade, e também, por estudiosos do processo de formação docente (Borba, 200 I; Dominicé, 1990; Kenski, 1994; Mindal, 2003; Nóvoa, 1992; Souza, 2003). O relato das histórias vivenciadas é uma forma de trazer à tona como fomos construídos ou como estamos continuamente nos reconstruindo no próprio ato de relatar histórias para diferentes interlocutores em outros momentos e espaços (Lopes, $200 \mathrm{I}$ ). Assim sendo, a análise de relatos autobiográficos dá acesso à construção das identidades sociais no momento de sua realização. É uma escolha coerente com a proposta do programa que via, no domínio da escrita, um instrumento valioso para o desenvolvimento conceitual e afetivo dos professores, e, no tema "iden-

I. Neste texto a sigla ADI será utilizada para referir-se aos auxiliares de educação infantil.

2. O Programa foi gerido pela Fundação Vanzolini e transcorreu no período de 2002-2004. 
tidade", um conteúdo que integrava a formação como um todo em um momento socioistórico importante para a área.

Neste trabalho, buscamos estudar a construção da identidade docente como um fenômeno em constante transformação, que ocorre a partir de práticas sociais específicas que medeiam a criação de discursos conforme cada professora em formação faz uso de instrumentos cognitivos, afetivos e lingüísticos, e cria motivos e vontades em um ativo processo para se referir a aspectos de um mundo partilhado intersubjetivamente. Desse modo, tomaremos por base a análise "genética" e buscaremos relações entre condições passadas e presentes, entre os eventos singulares relatados e outros planos da cultura, das práticas sociais, dos discursos circulantes, das esferas institucionais, da cultura do curso. O objetivo é apreender as marcas desses planos, bem como as marcas dos sujeitos na escrita de cada memorial. Os discursos serão analisados não apenas segundo sua coerência e legibilidade, mas também em relação a descontinuidades, ambigüidades, traços de outros discursos que possam conter.

\section{CONTEXTO}

Políticas educacionais têm cada vez mais destacado a formação docente como ponto básico do aperfeiçoamento do processo escolar em todos os níveis (Alarcão, 2003; Maués, 2003). No caso da educação infantil, isso é particularmente importante por ser um campo de trabalho que, pelas condições históricas de sua constituição, muitas vezes, é assumido por leigos, dentro de uma visão de atendimento à criança pequena que prioriza proporcinar-lhe cuidados físicos mais do que seu desenvolvimento global. Daí que esforços têm sido feitos para garantir formação docente adequada a todos que atuam na área, de modo a mediar mudanças nas práticas dos educadores (Barreto, 1994). Constatado o grande número dos educadores de creche e pré-escola que não possui sequer o nível mínimo de escolaridade requerido legalmente ${ }^{3}$ no país, a partir da Lei de Diretrizes e Bases da Educação 9.394/1996, vários municí-

3. De acordo com o Instituto Nacional de Estudos e Pesquisas Educacionais - Inep - , em 2003, no Brasil, o percentual de profissionais que atuavam em creches com formação em nível superior era de 17,67\% e, em pré-escolas, era de 31,29\% (www.inep.gov.br). 
pios têm buscado criar oportunidades para que eles adquiram formação de magistério em curso superior ou no curso normal de nível médio.

O Programa ADI-Magistério propôs-se a fazer a mediação com os professores no seu processo de construir novas atitudes diante do estudo e da profissão, dando prosseguimento à escolarização dos educadores dos centros de educação infantil que atuavam como professores leigos, de acordo com o novo quadro legal, e assegurando a eles oportunidades de progressão na carreira, agora vinculadas a novos patamares de qualificação profissional.

Participaram do programa duas turmas de alunos. A primeira reuniu 850 ADIs que haviam concluído apenas o ensino fundamental. Eles foram distribuídos em cinco escolas-pólo, localizadas em diferentes regiões do município para se submeterem a uma carga horária de 2.800 horas, a ser cumprida em dois anos, sendo 800 horas destinadas a atividades práticas. A segunda turma incluiu 2.750 alunos com ensino médio completo, em doze escolas-pólo, localizadas em diferentes regiões de São Paulo, com carga horária de 1.600 horas, a ser cumprida em um ano, sendo 800 horas destinadas à realização de atividades de Prática Educativa.

O programa era presencial e foi aprovado pelo Conselho Municipal de Ensino. As aulas das duas turmas eram dadas de segunda a sexta-feira, no período noturno, e, aos sábados, pela manhã, tendo sido organizadas 106 classes de aproximadamente 34 alunos cada uma. As aulas, planejadas por consultores de áreas específicas, eram ministradas por professores da rede municipal de ensino, preparados e supervisionados por educadores com larga experiência em formação docente.

A meta em relação a cada ADI era apoiar mudanças de concepções, atitudes e práticas referentes às crianças matriculadas nos centros de educação infantil e às suas famílias, conforme eram criadas situações mediadoras da apropriação de conceitos e habilidades interdisciplinares para a reflexão sobre o próprio trabalho.

O estudo analisou as produções da primeira turma de alunos, que era composta por mulheres (havia apenas um homem matriculado, daí a decisão de usar o gênero feminino para nos referir aos participantes do curso). Delas, $41,6 \%$ tinham idade entre 4 I e 50 anos, sendo que 34,2\% tinham mais de 50 anos e apenas $7 \%$, menos de 35 anos. Eram casadas ou moravam com companheiros $62,8 \%$ das ADIs, e 90, I \% delas tinham filhos. Estavam no trabalho 
em creches há muito tempo: 8 I\% delas trabalhavam entre II e 20 anos, I5,7\% tinham mais que 20 anos de serviço e apenas 2,3\% trabalhavam há menos de 10 anos na área. Muitas das ADIs (52\%) relatavam ter tido história de fracasso escolar, 31\% haviam deixado de estudar há mais de 20 anos e apenas 4\% estavam fora da escola há menos de cinco.

A partir de conteúdos formativos das áreas curriculares - Linguagens e Códigos, Matemática e Estatística, Ciências Humanas, Ciências da Natureza, Fundamentos da Educação, Políticas Públicas, Organização do Trabalho Pedagógico e Orientação da Prática Educativa -, organizados ao redor de eixos temáticos, o cotidiano da formação foi planejado para garantir situações variadas e articuladas de aprendizagem, voltadas para a apropriação de conceitos e habilidades comuns e específicos das áreas. Foram realizadas aulas coletivas, promovidos encontros para desenvolvimento de projeto interdisciplinar que levasse à síntese de conhecimentos; porporcionadas vivências culturais e oficinas didáticas nas áreas de Literatura, Música, Cinema, Artes Plásticas, Teatro, Dança e Movimento, visitas monitoradas a museus e a outros espaços culturais e de divulgação científica, sessões de debates sobre filmes; foram ainda feitos seminários ou teleconferências com participação de especialistas convidados.

\section{CORPUS E METODOLOGIA DE ANÁLISE}

método de história de vida tem sido usado nas ciências humanas para captar a face interna da experiência humana, conhecer o rearranjo e a reapropriação do social que cada pessoa faz em seu relato e apreender as continuidades e rupturas reconhecidas pela pessoa (Marre, 1991). Narrativas autobiográficas funcionam como contextos de produção de significados pessoais a respeito de situações social e historicamente vividas e criadas no espaço comum das pessoas, nas trocas dialógicas que elas estabelecem (Hermans, Hermans-Jansen, 1995; Qi-Wang, Brockmeier, 2002).

Narrar sua história é um meio de cada pessoa atribuir um sentido à sua experiência, dar um significado a quem ela é e perceber como este é construído no mundo social. Isso ocorre à medida que a narrativa organiza um discurso em que se imbricam significações diversas, que formam redes e criam uma realidade social no embate com diferentes interlocutores (reais ou internalizados) para legitimar sentidos. 
A análise de narrativas dá acesso aos modos de construção de identidades sociais a partir de cânones ou exceções da cultura, considerando a historicidade das instituições em que as práticas dos sujeitos se situam (Lopes, 200 I). Tal análise visa a apreender as várias vozes trazidas pelos participantes, para estruturar sua narrativa e investigar de onde elas emergem, como elas se misturam, se transformam e são usadas para o narrador construir um sentido de si a partir dos conflitos, oposições, negociações de sentido e cooperações entre os papéis que tomam para si e as diferentes posições que elas expressam (Hermans, 2002; Lemos, 2002; Molon, 2002; Oliveira, Guanaes, Costa, 2004).

Assim como cada professor usa instrumentos mediadores internos para refletir sobre a totalidade da situação e construir, por exemplo, uma narrativa, em um processo em que a relação entre pensamento e linguagem é de recíproca constituição (Vygotsky, 200 I), também o pesquisador deve utilizar determinados instrumentos - conceitos, procedimentos, ou seja, uma perspectiva teórico-metodológica - para analisar os discursos do professor sobre sua prática e construir um discurso sobre os complexos fatores que possivelmente fazem a mediação com a situação investigada (Newman, Holzman, 2002).

Neste trabalho, orientados pela perspectiva teórico-metodológica denominada "rede de significações", proposta por Rossetti-Ferreira et al. (2004), desenvolvemos a análise de uma amostra de memoriais elaborados por alunos do Programa ADI-Magistério. Buscamos investigar como a discursividade de cada um dos textos produzidos construiu identidade(s) por meio de estratégias enunciativas específicas em espaços institucionais e históricos determinados. Nesse sentido, a construção da identidade é compreendida como um processo contínuo que ocorre no fluxo das atividades sociais. Mais do que instâncias estanques, as identidades precisam ser compreendidas dentro de relações carregadas de poder e, por isso mesmo, ser caracterizadas como relações de subordinação, cooperação ou competição, a depender do contexto e dos interlocutores.

Pensar a construção da identidade da perspectiva da rede de significações nos afasta de um entendimento linear dos modos de relação entre as identidades e nos leva a conceber cada posição identitária articulada com outras linhas de identidade numa teia de relações e disposições sociais e históricas. 
A noção de "rede de significações" representa todos os sentidos que compõem o mundo para nós, não como soma, mas como um "sistema" em que cada sentido é determinado na sua relação com os outros; um mundo de significados latentes de que os sentidos de nossas percepções e pensamentos atuais são concreções singulares e provisórias. Como a rede não pode ser assumida como figura, nossas significações terão sempre um lado oculto para nós (além da obscuridade própria do Ser), e sua permanência ou mudança está menos no plano representacional da existência, ou nos significados claros de nossa linguagem, do que no sentido de nossa forma de agir, sentir e perceber. Quando agimos ou nos comportamos é toda a rede que atualizamos ou modificamos, embora estejamos explicitamente presentes apenas [em relação a] significados ou situações pontuais. (Furlan, 2004, p.5I-52)

A depender do contexto discursivo, determinada posição identitária é destacada sem, contudo, perder de vista sua relação com outras posições, assim como os discursos, valores e crenças relativos a cada uma. A identidade docente aparece assim articulada às identidades de gênero, familiares, religiosas, raciais, de classe, que são carregadas de contradições, cujas marcas socioistóricas aparecem nos relatos (orais ou escritos) que as pessoas fazem de si. Além disso, a construção da identidade jamais é concebida como um processo isolado. Existe sempre uma relação com o(s) outro(s) - concreto ou virtual, real ou imaginário, específico ou genérico - para quem se apresenta e, por isso mesmo, é mais que tudo um acontecimento social e coletivo.

No que concerne ao objeto de discussão deste trabalho, qual seja, a construção da identidade docente dos professores de crianças de zero a seis anos de idade, a perspectiva de rede de significações aproxima-se dos trabalhos de Sarmento (1999). Para a autora, refletir sobre identidades profissionais e pessoais de educadoras de creche significa analisar um processo de construção social em que cada educadora, como ator social, individualmente joga a sua história de vida com a história de vida do grupo a que pertence, com as crianças, com as comunidades e com os contextos nos quais se desenvolve a sua ação e formação educativa, transformando essa teia de interações numa forma própria de ser e agir. Ainda para Sarmento, o processo de construção de identidade não é solitário: faz-se em contextos, em interações, com trocas, aprendizagens e relações diversas das educadoras com os seus vários contextos de vida. 
Trabalhamos com 33 textos (4\% do total) de ADIs alunas que participaram da primeira turma do programa, ou seja, aqueles que tinham completado apenas o ensino fundamental antes do referido programa de formação. Tais textos compunham um memorial em que as alunas eram convidadas a traçar sua trajetória pessoal em relação a seis tópicos: Quem sou eu, Minha vida escolar, Minha vida no CEI, Minha vida no ADI-Magistério, Minha prática educativa e Meu futuro como professor(a). A produção de relato foi manuscrita. Os textos da amostra, todos de mulheres, foram digitados de modo a tentar manter, na medida do possível, as suas características, aspectos que irão aparecer na apresentação de extratos que usaremos na análise.

\section{APENAS UM NOVO OLHAR SOBRE O QUE JÁ SE FAZIA?}

Os trechos selecionados procuram indicar que as escolhas feitas pelas ADIs para representarem a si mesmas trazem marcas significativas cunhadas na cultura e na participação no programa. São marcas identificáveis quando elas se referem ao curso e também quando descrevem momentos anteriores a ele.

Ao ler tais relatos, é possível reconhecer traços da história de profissionalização das ADIs, mulheres provenientes de camadas populares que, na maioria das vezes, ainda muito jovens, tiveram que deixar os estudos para ajudar no orçamento doméstico ou foram excluídas e reprovadas pela escola. Os relatos de suas experiências, afirmam, na maioria das vezes, que essas mulheres começaram a trabalhar ainda na adolescência como costureiras, recepcionistas, telefonistas, caixas de supermercado, operárias em fábricas de papelão, metalúrgicas, serventes em hospital. Atividades de cuidado e restritas ao âmbito doméstico, hegemonicamente desempenhadas pelas mulheres na sociedade, também aparecem como modos de iniciação ao trabalho, tais como as de domésticas, babás, auxiliares no cuidado de irmãos etc.

Todas essas atividades guardam relações com a atividade atual, seja pela pouca qualificação até então exigida dos que se inscreviam para ser ADIs, seja pela feminização da atividade de cuidado e educação de crianças de zero a seis anos. Por intermédio delas, as ADls se iniciaram no cuidado de crianças e, por vezes, conseguiram uma "formação" que as orientasse para o trabaIho em creches. 
- Desde adolescente cuido de crianças.

- Já tinha alguma prática com crianças, porque eu cuidava de um irmão mais novo adotivo e duas sobrinhas.

- Já me sentia uma profissional porque antes trabalhei muito com criança, só que em pediatria hospitalar; só que a diferença é que nos CEls as crianças são sadias.

Além do entrelaçamento com a questão de gênero, há aquele relativo à questão da origem socioeconômica do grupo. A escolha do trabalho nas creches e o ingresso no serviço público representariam a oportunidade de um serviço remunerado, que pressupunha uma função semelhante às funções até então realizadas, possibilitando certa ascensão social. Assim, a entrada no CEl poucas vezes obedeceu a uma decisão consciente do que seria a tarefa, ora imaginada com parâmetros do trabalho já feito com crianças, ora assentada no discurso de que basta ser mulher para cuidar de criança.

Os relatos das alunas apontaram um modo de descrever a função, anterior ao programa, marcado por representações decorrentes de uma visão assistencialista de atendimento à criança pequena, que priorizava o cuidado físico mais do que uma estimulação global a seu desenvolvimento. Quanto às tarefas que realizavam na creche, foram assim definidas antes do programa:

- Cuidava da higiene das crianças e de sua alimentação e seu bemestar.

- Cuidando das crianças com amor, dando a elas carinho amor, atenção alimentando/higiene/brincando.

- Dar alimentação, o banho e o lazer, sistema de assistência social.

- Receber as crianças, café, cuidar de suas necessidades fisiológicas, limpar, dar algumas atividades sem objetivos, mantê-las "aparentemente saudáveis" e felizes.

A escolha dessa forma de relato mostra um posicionamento sobre as discussões referentes a cuidado/educação características da área, algumas vezes mais próximo a uma visão já ultrapassada, que fragmenta cuidado e educação; outras vezes revela um discurso mais afinado com a proposta do curso, 
que assumia clara postura de não polarização ou priorização de um ou outro elemento desse binômio.

Outro posicionamento que demonstra as marcas do curso refere-se às possibilidades suscitadas para pensar a relação teoria e prática. De uma perspectiva descritiva, pode-se dizer que os depoimentos apontaram haver no período anterior ao curso uma ausência de formação ou uma formação carente de teorias que informassem as ADls sobre os motivos de certas ações.

- Nenhuma noção, somente a experiência de mãe, carinho e atenção e atendendo suas necessidades.

- Nossa função só era vista como cuidar, mas sempre trabalhamos com planejamento e seguíamos sem saber o porquê, pois nos faltava a teoria.

Os relatos indicam diferentes apropriações do binômio teoria-prática: ao narrar como desempenhavam suas atividades, as ADIs ou as descreviam como ausentes de qualquer teoria e sujeitas a erros, ou as qualificavam positivamente, dizendo que Ihes faltava apenas a nomeação daquilo que já faziam, a sustentação de um conhecimento sistematizado. Admitem ter muita prática e pouca teoria. Embora sem formação específica, afirmam-se como pessoas que faziam coisas próximas das propostas pelo curso, mas desconhecendo os critérios para avaliar as atividades. $\bigcirc$ relato torna-se oportunidade de justificarse e assume, algumas vezes, um tom de lamento:

- Eu ensinava, dava atividades, mas não tinha conhecimento do que estava fazendo, se era certo ou errado.

- Eu desenvolvia minhas atividades sem um porquê, ou para que, só sabia que era certo, sempre gostei de cantar, brincar, contar história e promover oficinas de artes com as crianças.

- Eu gostava muito de dar trabalhos para a criança fazer com folha de papel sulfite, colagem, pintura, mas não entendia nada bem não. Só cuidar, no banho, no parque, e na alimentação, um trabalho sem planejamento.

- Eu fazia quase tudo o que faço hoje, mas não tinha uma formação especial ou profissional para trabalhar com crianças, principalmente na parte pedagógica. 
Conhecer teoria, saber as razões de uma atividade, avaliar se as práticas executadas eram certas ou não, parecem ser elementos que orientam as falas das alunas, que fazem uso de termos como "parte pedagógica", "dar atividades", "cuidar", "formação especial ou profissional". ○ uso freqüente da conjunção adversativa permite inferir a importância que a teoria assume no discurso das educadoras em formação: para as ADls, faz parte do ser professor, entender as ações, saber o porquê das coisas, avaliar alternativas. Esse saber é relatado como detido por técnicos, fragmentando teoria e prática. $\bigcirc$ reconhecimento da diferenciação desse discurso é ainda reforçado pelo lugar que elas ocupavam; toda a experiência é descrita como não autorizada e submetida ao consentimento de um detentor do saber pedagógico: professores ou técnicos da Secretaria (na época, a responsável pelas questões de assistência social), descritos como aqueles que assumiam para si o trabalho especializado ou que "passavam" certo conhecimento diferenciado. Nos discursos que as ADIs elaboraram sobre a experiência pessoal anterior ao curso, a identidade profissional aparece como resultado da ação no dia-a-dia, ao lado de informações passadas em reuniões e colocadas em prática:

- Começamos com a cara e a coragem, sem estudo, mas sempre nas creches havia uma professora ou pedagoga que nos orientava nas atividades.

- Mesmo não tendo tantas teorias, fui adquirindo a prática no dia-a-dia. Sempre tivemos reuniões com o pessoal da regional nas quais eram passadas informações que se referiam à área, e também tinham cursos nos quais pudemos aprimorar, e tudo que aprendia colocava em prática para dar um bom desenvolvimento às crianças.

- Também tínhamos professores para coordenar no lado pedagógico, com desenhos mimeografados.

Aos poucos, as ADIs passam a fazer uma avaliação que aponta para a concepção de que a apropriação de uma teoria, articulada a um saber prático, compõe plenamente a identidade docente. Faz parte do ser professor planejar e organizar a ação pedagógica; saberes que são tomados como referência para se compreender aquilo que era inadequado no passado. É dessa perspectiva que as ADIs avaliam suas dificuldades anteriores ao curso: 
- A minha dificuldade era de trabalhar em grupo de crianças maiores, por não saber organizar atividades que envolvessem o grupo.

- Era difícil prender a atenção das crianças. Eu tinha paciência, mas não tinha técnicas de planejamento para elaborar as atividades.

- (Dificuldade de) registrar ou relatar o que acontecia com as crianças e, nas reuniões, às vezes não conseguia expressar minhas opiniões.

- Minha dificuldade sempre foi de colocar no papel, fazer registros, enfim, conhecer as teorias, saber que a criança aprende brincando. $\bigcirc$ que eu não gostava de fazer era dar para elas aquelas folhas mimeografadas.

Se essa relação entre teoria e prática é importante quando relatam suas funções antes do curso, ela começa a tomar melhor forma quando as ADls falam diretamente sobre o programa e seus impactos. Na construção de um texto cujo interlocutor principal é o professor do curso, elas parecem se esforçar para construir um discurso com repertórios trazidos pelos conteúdos veiculados nas aulas, por seus professores e colegas, pelos textos que leram; repertórios próximos ao saber pedagógico instituído. Nesse esforço, algumas apropriações são mais e outras menos consistentes em relação à postura e ao projeto político pedagógico do curso, a um linguajar próprio de determinada área do conhecimento.

Um terceiro aspecto, que compõe a complexidade do material e que aponta para a construção de uma identidade do professor de creche, diz respeito à posição da criança, sujeito da ação docente. Aparece fortemente um discurso sobre a criança, ou melhor, um discurso sobre os olhares para a infância. Isso é relevante sobretudo quando lembramos que, no senso comum, a expressão "eu olho criança" serve para designar um cuidado não especializado à infância, um trabalho que não é o do professor. Talvez por esse motivo seja o tema "um novo olhar para a criança" o escolhido pelas ADls entre os diversos tratados no curso para se referir às aquisições por elas feitas. Elas contam:

- Nestas aulas que tivemos em todos esses semestres do curso, aprendi muito, percebo que os trabalhos das crianças têm um significado grande para elas. 
- O que mudou na minha prática educativa hoje foi a observação diária das crianças. Agora vejo tudo de uma maneira mais pedagógica, estou sempre atenta para que os meus atos não venham trazer nenhum trauma ou constrangimento para as crianças, porque sei que isso elas vão carregar para o resto da vida.

- Aprendi a direcionar-me mais para o desenvolvimento de habilidades, sociabilidade, comunicação das crianças. De nada adianta ela estar com perfeita saúde e não ser sociável, não saber explorar seus potenciais artísticos, comunicar-se com o grupo e educadores e saber se portar no meio do grupo.

- Não tinha a prática de olhar as produções e analisar os avanços que as crianças conseguiam dia após dia ao desenvolver as produções.

- Descobri que as atividades de seqüências são de grande importância em que as crianças podem desempenhar melhor as produções porque praticam dia-a-dia. Isso facilita para que eles acabem se envolvendo, tomando gosto pela atividade, que se torna mais prazerosa, aprendem melhor. Em relação a mim, mudei meu modo de pensar com um novo olhar tanto para a criança como em relação às atividades, acolho com carinho.

- Ver o trabalho de cada um com outro olhar, observando seu desenvolvimento, proporcionando-Ihe atividades contínuas, para fixação e compreensão da criança, valorizando o seu trabalho e incentivando a criança em cada produção. Aprendi a valorizar e arquivar, também, os trabalhos, para que os pais também tivessem a satisfação de apreciá-los.

Nesse processo de relatar modificações nas práticas, marcadas por maior planejamento, melhor organização e novos modos de olhar a criança, as ADIs também descrevem mudanças em relação a si mesmas, como profissionais. Ao fazerem tal descrição, aproximam-se de um discurso que define a atividade docente como planejamento, registro, organização, acompanhamento da criança, discurso esse que permeou a formação. Ou seja, começam a utilizar um repertório que identifica a função desempenhada mais como uma profissão propriamente dita e menos como atividade pouco reflexiva, pouco planejada, realizada sem a necessidade de uma avaliação. As ADls recorrem a termos como "sala", "registro", "seqüência de atividades", "atividades pedagógicas", 
"cantinhos", bastante diferentes dos utilizados para a descrição da função antes do curso.

- Minhas práticas educativas são sempre refletidas e questionadas, do tipo: Como foi? Houve prazer? Houve aprendizado? $\bigcirc$ que ficou de bom? Que deve ser revisto? $\bigcirc$ que deve ser reforçado? E assim busco sempre melhorias no meu trabalho, sempre visando ao bem-estar da criança (...) outra dificuldade que percebi durante os estudos é que desavisados por esse ou outro motivo quebramos muito a seqüência do nosso trabalho do dia-a-dia e a escolha dessas seqüências me fez perceber o quanto é maior o aprendizado quando fazemos o trabalho com uma seqüência mais próxima, ou seja, em curto período de tempo, as crianças têm um aprendizado melhor.

- Houve muitas e relevantes mudanças na minha vida profissional e destaco a necessidade do registro das atividades pedagógicas que, antes, não eram presentes na minha rotina, mas hoje se mostram importantes, pois através delas tomo ciência de como vai o desenvolvimento da minha sala, e a partir daí posso planejar o quê e o como desenvolver atividades que supram as necessidades de aprendizado das crianças. $\bigcirc$ hábito do registro é um importante instrumento para o preparo tanto das atividades permanentes como didáticas. Ele também tem me auxiliado na elaboração de uma rotina flexível, porém planejada, em que o improviso perde cada vez mais o seu espaço.

- Faço exposições na sala, convido as outras crianças e os pais para visitarem. Nunca deixo de colocar o nome do autor em cada produção. Procuro planejar as atividades com antecedência, organizando o espaço e os materiais. Quanto à prática educacional, procuro interferir o mínimo possível deixando a criança expor sua criatividade, coisa que no passado não conhecia o efeito da intervenção. Fica claro afirmar que intervir significa limitar, fazer com que a criança se torne apenas um reprodutor e não um criador. $\bigcirc$ resultado disso está nas exposições, quando eles reconhecem seus trabalhos. Aquilo que parecia um rabisco tornou-se arte, ou seja, tudo que foi colocado em uma folha de papel passa a ter uma grande importância. Todos se sentem valorizados e importantes. Esse é o papel do educador. 
- ... a criação dos cantinhos, que são feitos com mesas e cadeiras, que possibilitam a criança escolher a atividade que ela desenvolve (por exemplo: pinturas diversas, massinha, colagens e recortes, montatudo), faz com que a atividade seja prazerosa. Não sendo imposta para a criança, se torna acolhedora, pois reúne ali seus amiguinhos.

- A mudança que estou percebendo é que agora, quando estou aplicando uma atividade, tenho certeza que está certo, pois estou seguindo um planejamento de acordo com a faixa etária daquelas crianças. Isso é muito gratificante para mim, porque amo o que faço, que é trabalhar com crianças.

- A Orientação da Prática Educativa me ajudou a criar minhas atividades, através de um planejamento que eu pudesse separar materiais, usar uma estratégia, buscar um objetivo e avaliar não só a criança como também a mim mesma.

Conforme relatam ter assumido nova perspectiva para seu trabalho, é possível observar que as ADls apontam novas significações em relação à tarefa no Centro de Educação Infantil e ao papel de professor:

- Creio que a primeira mudança foi tomar consciência de que minha prática, querendo ou não, era educativa. Conseqüentemente tudo o que eu fizesse seria observado pelas crianças e com toda certeza reproduzido mais tarde, com total perfeição. A partir dessa primeira, comecei a me policiar mais, observando meu falar e agir, tendo ciência da sensível percepção que as crianças têm para captar tudo que ao redor delas se passa. Esse foi um dos marcos importantes em minha prática, isto é, passei a ser mais consciente dos meus atos.

- Hoje em dia acho que eu mudei e que não é só cuidar, também é educar. É mostrar à criança que ela é capaz de pensar, fazer e concluir, é proporcionar desafios para que ela cresça um adulto mais consciente. $\bigcirc$ que eu mudei na minha prática é que eu tenho mais que tirar das crianças, não dar tudo feito para ela fazer.

- O que eu mudei é que tive oportunidade de demonstrar tudo o que aprendi. A importância da identidade e da auto-estima, do agir e interagir com as crianças, da liberdade que devemos dar a elas de 
pensar e expor seus pensamentos (e essas idéias que vêm do seu nascimento), do valor das histórias e cantos, e de como meu trabaIho pode ser alienado, da cidadania e solidariedade em nosso ambiente de trabalho.

- Relendo minhas produções de orientação da prática educativa e examinando nessa escolha, pude considerar como mudei meu modo de agir até o de pensar. E colocando tudo em prática, posso alcançar meus objetivos, transmitir com determinadas atividades, que me proporcionam uma sondagem da minha turma, garantindo a aprendizagem adequada a elas, pois pude perceber suas necessidades e pontos de melhora.

- Eu mudei em quase tudo porque eu achava que às vezes era certo, mas tinha sempre algo que era incerto e eu não conseguia ver, e este curso me ajudou a encontrar outros caminhos para essas complicações, clareando mais a minha mente para as atividades.

Por vezes, o relato da mudança reconhecida pela ADI recai sobre o lado pessoal, apontando novos aspectos naquilo que reconhecem como o "sentido de si".

- Eu mudei muito porque eu não gostava de cantar, agora eu sou outra pessoa, mais feliz, gosto do que faço, procuro melhorar cada vez mais. Foi muito bom para mim. Eu era uma pessoa muito fechada e quero continuar meus estudos cada vez mais.

- Entre muitas coisas que aprendi, consigo desenvolver e criar coisas novas, como as produções que fiz e, que me ajudaram a amadurecer. Hoje consigo ver coisas que antes não via, me achava insegura, hoje me sinto segura nas atividades que proponho.

\section{SUBMETIMENTO E RESISTÊNCIAS: A CONSTRUÇÃO DA IDENTIDADE}

Mediante os recortes apresentados, podemos considerar que a atividade de elaborar uma narrativa ao final de um curso de formação docente com extensa carga horária cumprida em atividades variadas mostrou-se um excelente contexto para a produção de significados pessoais relacionados a diferentes 
situações vividas social e historicamente. Esse processo de produção de texto escrito envolveu trabalhar as concepções, muitas vezes ambíguas, expressas em frases cheias de confrontos, em que aparecem incompreensões, descrenças, ao lado de perspectivas e compromissos.

A matriz socioistórica que atravessa essa produção pode ser assim resumida: o momento de transição das creches para a Secretaria de Educação criou a oportunidade de realização do programa. Este parece ter contribuído para que as ADls atribuíssem novos sentidos ao seu modo de ser durante o processo de se formar como docentes. Um aspecto importante foi o fato de as alunas adquirirem formal e efetivamente sua qualificação profissional, em termos de competências e de enquadramento na carreira do magistério, e de, assim, alcançarem um status que lhes tinha sido, até então, negado historicamente. Mais ainda, o alcance da mudança foi por elas ampliado ao se perceberem ocupando uma função importante junto às crianças e ao constatarem ter obtido ainda ganhos em competências profissionais e escolares que as estimulavam a prosseguir estudos em nível superior.

Sendo a identidade cunhada na experiência que se refaz em cada professor como uma pessoa singular (Gonçalves, 1996), ela não se restringe ao mundo do trabalho, mas atua sobre outros processos de identificação e diferenciação ligados ao papel da mulher, à visão de família, casamento, direitos de cidadania, dentro de determinadas condições, ou seja, a partir do trabalho sobre uma matriz socioistórica. A história de construção da área permite dizer que o modo pelo qual ocorrem as relações de gênero e se definem os espaços e as atividades autorizados para as mulheres em nossa sociedade caracteriza um importante cenário de construção das identidades profissionais dessas ADls.

Em relação à produção dos relatos, deve-se considerar que eles podem ter sido limitados pelo fato de se tratar de um trabalho de conclusão de curso, em que, provavelmente, cada aluna deve ter-se esforçado para se apresentar aos professores, seus interlocutores primeiros, como profissional do ensino que domina determinados conteúdos, o que é de certa forma, inerente à participação em processos de formação. Contudo, se algumas mudanças são assumidas e se formas elaboradas de discurso são mais percebidas nos relatos que tratam diretamente sobre o curso, é importante refletir sobre a contribuição do programa para esse fato. 
O desenho curricular traçado para o programa foi apresentado em outro trabalho (Oliveira et al., 2004) e partiu de um conjunto de elementos: os conhecimentos que as alunas traziam, os que deveriam ser apropriados, as competências, habilidades e atitudes a serem desenvolvidas a partir das metodologias organizadas, os materiais, recursos, espaços e tempos para aprender, o processo de avaliação etc. Segundo esse desenho, a formação docente buscou abrir espaço para a mudança de práticas e concepções, elaboradas na experiência direta de trabalho por muitos anos. Essa população de alunas - testemunha da emergência, por vezes lenta, mas muito cheia de conflitos quanto às novas perspectivas para a educação em creches, as quais se opunham radicalmente às práticas assistencialistas que marcaram o histórico da área - era desafiada a dominar novos referenciais para a tomada de decisões em sua prática pedagógica.

O modelo de ensino defendido apoiava-se em uma visão socioistórica do desenvolvimento humano e privilegiou as interações sociais como mediação fundamental na promoção de mudanças significativas nas capacidades das crianças de sentir, agir e pensar o mundo e a si mesmas. Daí a importância central de organizar situações de observação e de análise de episódios de interação envolvendo adultos e crianças no CEI pelas professoras em formação. Daí, também, o tema "um novo olhar para a infância" ser tão referido nas narrativas das alunas.

programa ainda buscou promover a apropriação de itens significativos do conhecimento historicamente construído, visando capacitar as docentes a tratarem as questões profissionais de modo mais elaborado, além de subsidiá-las para mediar a curiosidade e a construção de saberes pelas crianças sobre o mundo das ciências, das artes, sobre o fantástico e sobre si mesmas. Além disso, para atuarem como mediadoras do processo de desenvolvimento da criatividade e imaginação da criança, as alunas do programa foram incentivadas a dominar diferentes linguagens presentes na expressão artística.

As situações de aprendizagem envolviam experiências diversificadas que estimulavam a iniciativa e a autonomia intelectual das professoras em formação e lhes ofereciam oportunidades de construir conhecimentos, habilidades e valores, de fortalecer o pensamento crítico, o raciocínio argumentativo, a sensibilidade pessoal, a capacidade para trabalhar em equipe, bem como de tomar decisões ao interagir com as crianças, seus familiares e colegas de tra- 
balho. Nas atividades trabalhadas nas aulas, as alunas eram estimuladas a investigar, comparar, discutir, anotar e justificar suas respostas. As atividades de estudo criadas colocaram-nas em posição de problematizar as situações de trabalho, sistematizar suas reflexões em várias formas de registro e reconstruir conhecimentos historicamente elaborados.

A realização de atividades em duplas, trios, ou grupos maiores, o constante estímulo para o registro escrito, para uma leitura criteriosa, para o levantamento de questões, punham cada aluna em posição de desenvolver um pensamento reflexivo. Nas atividades formativas das professoras do programa, procuravam acompanhar eventuais mudanças na rede de significações por elas elaboradas acerca da criança, de sua família, de seu próprio processo de escolarização e inclusão no mundo do trabalho e em sua concepção pedagógica. Pode-se pensar, portanto, que a estrutura do programa, ao organizar oportunidades para as alunas assumirem um papel protagonista em sua prática profissional, as tenha levado a repensar convicções pessoais e a refletir sobre suas condutas pedagógicas, desenvolvendo autoconfiança e autoconhecimento e recriando sua identidade docente.

Assim, o processo formativo que levou as ADls-alunas a refletirem sobre sua prática a partir dos conteúdos trabalhados nas diversas atividades criadas pelas áreas curriculares pode ter mediado o abandono de algumas posições cristalizadas sobre o trabalho em creches e a construção de um novo olhar sobre si mesmas e sobre o mundo, particularmente, sobre a criança e sua forma de aprender e se desenvolver. No primeiro caso, as descrições cristalizadas só aparecem quando as alunas relatam as atividades antes do curso. As novas construções, acompanhadas de um discurso mais elaborado, são feitas quando as professoras são convidadas a falar sobre a experiência com o curso. Assim, as ADls abriram em seus relatos novas rotas para a ação, estabeleceram novas prioridades, destacaram certas interdições, enfim, fortaleceram uma identidade docente.

A leitura dos relatos aponta alguns indícios de apropriação de um discurso renovado em termos de conteúdo e de forma argumentativa. Marcos conceituais básicos, como o "educar e cuidar", o "respeito à criança e a suas produções", apareceram. Não se trata de buscar a veracidade da fala dessas educadoras e/ou confrontá-la com suas práticas no interior dos CEls, mas de reconhecer que mudanças significativas são visíveis no nível do discurso sobre 
essa prática. $\bigcirc$ tratamento dado à área curricular denominada Orientação da Prática Educativa - OPE -, que promoveu uma programação estimulante de atividades que cada professor deveria desenvolver semanalmente com as crianças e que propôs o trabalho interdisciplinar das áreas curriculares pode ter conseguido reunir prática e teoria de um modo produtivo. Incentivou as alunas a ampliarem seu comportamento de pesquisa e reflexão sobre as dimensões éticas e afetivas da atuação docente, conseguiu orientá-las a sistematizar suas reflexões, usando várias formas de registro, bem como as levou a analisar os indicadores que tomavam para planejar situações de aprendizagem para as crianças. É provável que o caminho curricular escolhido, qual seja, o de propor atividades que ao serem problematizadas e compreendidas no decorrer do processo de ensino-aprendizagem das ADls as instrumentalizassem para o desempenho de sua ação pedagógica, tenha constituído um mediador fundamental.

O desenvolvimento das competências de observação das alunas, guiadas por novos filtros ideológicos, e o trabalho com a escrita, a literatura, os conhecimentos de matemática e de outras áreas do saber sistematizado, puderam favorecer o diálogo e a confrontação do saber por elas já produzido em outros momentos de sua vida profissional e pessoal com o conhecimento científico, ético, tecnológico, artístico trabalhado no programa.

trabalho que aliou o desenvolvimento das atividades do programa à reflexividade da ação humana (prática e teórica) pode ter contribuído para promover mudanças nas alunas e nas suas maneiras de entender as circunstâncias em que as ações ocorrem. As ADls passam a reconstruir para si mesmas o modo pelo qual agem em uma situação, os papéis que adotam, os significados que acham que lhes são atribuídos (Seeger, 200 I , p.49). Cada aluna, presa em seus motivos, lembranças, argumentos, conceitos, representações, intenções em relação ao(s) interlocutor(es), ao selecionar suas falas e organizar seu discurso, foi - conscientemente ou não - obrigada a diferenciar aspectos de sua experiência. A proposta do memorial favoreceu, assim, a confrontação das diferentes identidades que compõem cada história singular, atravessada pelas mediações históricas desse grupo cultural.

Ter a oportunidade de desenvolver essa reflexividade, ser ouvido e acoIhido em seus pontos de vista, pode ajudar cada professor em formação a ter maior controle sobre as próprias ações e reconhecer melhor os significados e 
sentidos envolvidos, os conflitos de papéis que tecem o drama humano coletivamente construído, tornando a relação teoria e prática elemento de uma pedagogia concreta (Kosik, 2002).

Se, para muitas alunas, o conteúdo do curso parecia familiar, o programa e a atividade de fazer um relato sobre ele thes proporcionaram uma inclusão crítica no saber sistematizado, servindo para que repensassem seu trabaIho cotidiano. Com isso, cada aluna teve a oportunidade de, e o contexto propício para, ao longo do programa, pôr em prática o que aprendia, testando, adaptando e transformando, produzindo conhecimento didático e pedagógico, percebendo-se como professora. Essa percepção pôde ser explicitada no momento de relatar as transformações ou permanências provocadas pelas experiências possibilitadas pelo curso.

\section{CONCLUSÃO}

trabalho que ora apresentamos nos remete a chamar a atenção para novos olhares que devem ser dirigidos aos trabalhos escolares. Neles, conforme Cardoso Jr. (2005), o aluno se esconde e se apresenta, busca e rejeita sentidos existenciais importantes para ele, o que requer dar voz a esse aluno, mais ainda, ouvir sua narrativa e abrir-se para apreender os seus múltiplos sentidos. Tais aspectos remetem a pensar na importante questão da autoria do texto.

Cada sujeito pode ser considerado autor conforme se assume como produtor de linguagem, submetido a regras das instituições e a determinadas condições de produção (Foucault, 1997; Oliveira et al., 2004). O exercício da escrita é pessoal, mas se engendra no interior de outros discursos da pessoa e de outros autores. Ao escrever, o indivíduo assume um papel em um drama que não conhece totalmente, conforme interage com outros interlocutores. É, portanto, algo singular e plural, dado que todo texto é um desdobramento de outros textos. Ele possibilita ao sujeito sair de si, perceber-se e produzir uma razão nova, subvertendo o já dito.

Embora se tenham sujeitado às condições que possibilitaram um determinado discurso, entendido como um acontecimento, algo que consiste em coexistência, dispersão, recorte, acumulação e seleção de elementos materiais descontínuos, as ADls se colocaram na posição de autoras do próprio texto, buscando produzir nele unidade, coerência, completude, ao mesmo tempo em 
que criavam efeitos de dispersão do sujeito e do sentido, abrindo caminho a muitas mudanças nelas mesmas.

\section{REFERÊNCIAS BIBLIOGRÁFICAS}

ALARCÃO, I. Professores reflexivos em uma escola reflexiva. São Paulo: Cortez, 2003.

BARRETO, Â. M. R. Por uma política de formação do profissional de educação infantil. Brasília: MEC/SEF/COEDI, 1994. Por que e para que uma política de formação do profissional de educação infantil? p. II - I5.

BORBA, A. M. A Metodologia pertinente ao estudo da identidade de professores na prática da avaliação escolar. Contrapontos. Itajaí, v. I, n. I . p.39-6I, 200 I.

CARDOSO JR., H. R. Para que serve uma subjetividade? Foucault, tempo e corpo. Psicologia: Reflexão e Crítica, v. I 8, n.3, p.343-349, 2005.

CHAIKLIN, S. The Category of "personality" in cultural-historical psychology. In: CHAIKLIN, S. (ed.) The Theory and practice of cultural-historical psychology. Aarhus: Aarhus University Press, 200I. p.238-259.

DOMINICÉ, P. L'Histoire de vie comme processus de formation. Paris: Harmattan, 1990.

FONTANA, R. C. Trabalho e subjetividade: nos rituais da iniciação, a constituição do ser professora. Cadernos CEDES, v. 20, n.50, p. 103-1 19, abr. 2000.

FOUCAULT, M. A Ordem do discurso: aula inaugural no Collège de France, pronunciada em 2 de dezembro de 1970. Lisboa: Relógio D’Água, 1997.

FURLAN, R. Corpo, sentido, significação. In: ROSSETTI-FERREIRA, M. C. et. al. Rede de significações e o estudo do desenvolvimento humano. Porto Alegre: Artmed, 2004. p.5 I-56.

GATTI, B. Formação continuada de professores: a questão psicossocial. Cadernos de Pesquisa, n. I 19, p. 191-204, jul. 2003.

GONÇALVES, L. A. O. Trabalho docente e subjetividade: embate teórico e novas perspectivas. Revista da Faculdade de Educação. São Paulo, v.22, n.2, p.43-7I , jul./dez. 1996.

HERMANS, H. J. M. The Dialogical self as a society of mind: an introduction. Theory and Psychology, v. 12, n.2, p. 147-160, Apr. 2002,

HERMANS, H.; HERMANS-JANSEN, E. Self narrative: the construction of meaning in psychotherapy. New York: The Guilford Press, 1995. 
KENSKI, V. M. Memória e ensino. Cadernos de Pesquisa, n.90, p.45-5I, ago. 1994.

KOSIK, K. Dialética do concreto. 7.ed. Rio de Janeiro: Paz e Terra, 2002.

LEMOS, T. V. Graciliano Ramos. a infância pelas mãos do escritor: um ensaio sobre a formação da subjetividade na psicologia sócio-histórica. Juiz de Fora: Editora UFJF; Musa, 2002.

LOPES, L. P. M. Práticas narrativas como espaço de construção das identidades sociais: uma abordagem sócio-construtivista. In: RIBEIRO, B. T.; LIMA, C. C.; DANTAS, M. T. L. (orgs.) Narrativa, identidade e clínica. Rio de Janeiro: Ipub, Cuca, 200 I . p. 55-7I.

MARRE, J. L. História de vida e método biográfico. Cadernos de Sociologia. Porto Alegre, v.3, n.3, p.89-141, jan./jul. 1991.

MAUÉS, O. C. Reformas internacionais da educação e formação de professores. Cadernos de Pesquisa. São Paulo, n. I 18, p.89-1 17, mar. 2003.

MINDAL, C. B. O Memorial como instrumento pedagógico na formação de professores. Psicologia da Educação. São Paulo: PUC-SP, n. I6, p.25-34, 2003.

MOLON, S. I. Entrelaçando a psicologia e a pedagogia: uma reflexão sobre a formação continuada de educadores à luz da psicologia sócio-histórica. Contrapontos. Itajaí, v.2, n.5, p.215-225, maio/ago. 2002.

NEWMAN, F;; HOLZMAN, L. Vygotsky: cientista revolucionário. São Paulo: Loyola, 2002. NÓVOA, A. (org.) Vidas de professores. Porto: Porto Editora, 1992.

OLIVEIRA, E. C. de. Autoria: a criança e a escrita de histórias inventadas. Londrina: Eduel, 2004. OLIVEIRA-FORMOSINHO, J. O Desenvolvimento profissional dos educadores infantis: entre os saberes e os afetos, entre a sala e o mundo. In: OLIVEIRA-FORMOSINHO, J.; KISHIMOTO, T. M. (orgs.) Formação em contexto: uma estratégia de integração. São Paulo: Pioneira; Thomson Learning, 2002. p. 4I-88.

OLIVEIRA, Z. M. R. Educação da espontaneidade: uma perspectiva na formação do professor. São Paulo, 1978. Dissert. (mestr.) PUC-SP.

OLIVEIRA, Z. M. R.; GUANAES, C.; COSTA, N. R. Discutindo o conceito de "jogos de papel": uma interface com a "teoria do posicionamento". In: ROSSETTI-FERREIRA, M. C. et al. Rede de significações e o estudo do desenvolvimento humano. Porto Alegre: Artmed, 2004. p. 69-80.

OLIVEIRA, Z. M. R. et al. Desafios no planejamento curricular de programa de formação pedagógica de educadores de creches em curso normal de nível médio. Contrapontos. Itajaí, v. 4, n. I, p.43-56, jan./abr. 2004. 
ONGARI, B.; MOLINA, P. A Educadora de creche: construindo suas identidades. São Paulo: Cortez, 2003.

PERRENOUD, P. A Prática reflexiva no ofício de professor. profissionalização e razão pedagógica. Porto Alegre: Artmed, 2002.

QI-WANG; BROCKMEIER, J. Autobiographical remembering as cultural practice: understanding the interplay between memory, self and culture. Culture and Psychology, v. 8, n. I, p. 45-64, Mar. 2002.

ROSSETTI-FERREIRA, M. C.; AMORIM, K. S.; SILVA, A. P. S.; CARVAlHO, A. M. (orgs.) Rede de significações e o estudo do desenvolvimento humano. Porto Alegre: Artmed, 2004.

SARMENTO, T. Identidade profissional de educadores de infância. Cadernos de Educação de Infância, n.52, p. I2-26, 1999.

SCARPA, R. Era assim, agora não: uma proposta de formação de professores leigos. São Paulo: Casa do Psicólogo, 1998.

SEEGER, F. The Complementarity of theory and praxis in the cultural-historical approach: from self-application to self-regulation. In: CHAIKLIN, S. (ed.) The Theory and practice of cultural-historical psychology. Aarhus: Aarhus University Press, 200 I. p.35-55.

SOUZA, J. V. Narrativas de professores e identidade docente: o memorial como procedimento metodológico. Psicologia da Educação. São Paulo: PUC-SP, n. I 6, p. I I-24, 2003.

VYGOTSKY, L. S. A Construção do pensamento e da linguagem. São Paulo: Martins Fontes, 2001 .

Recebido em: maio 2006

Aprovado para publicação em: maio 2006 